\title{
Acute cholangitis complicating a chronic alveolar echinococcosis: an unusual therapeutic cholangioscopy
}

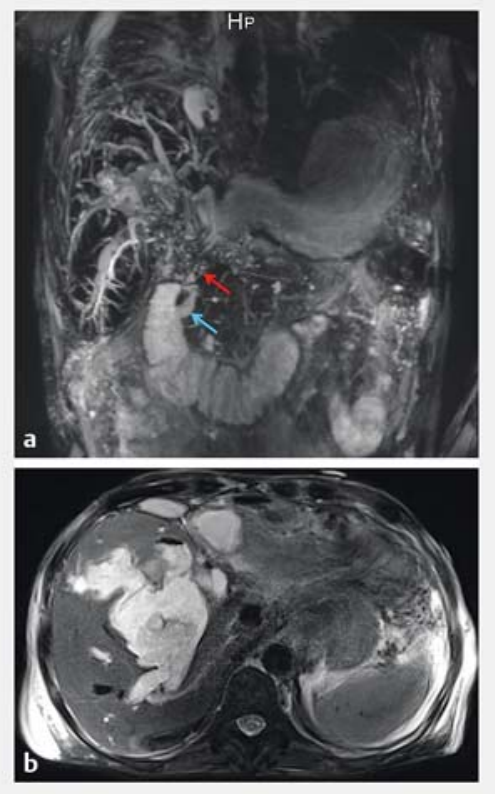

> Fig. 1 Magnetic resonance cholangiography showing: a the main bile duct (blue arrow) and a multicystic parasitic pseudotumor (red arrow); b an intrahepatic necrotic parasitic cavity, in communication with dilated intrahepatic bile ducts, and containing gallstones.
A 71-year-old man with a history of chronic alveolar echinococcosis presented with acute cholangitis and severe sepsis. Echinococcosis had been diagnosed 38 years previously. At this time, a left hepatectomy, associated with distal gastrectomy and gastro-jejunal anastomosis (Finsterer) was performed. Afterwards, despite parasitostatic therapy, the infection progressed slowly with chronic biliary compression, causing secondary biliary cirrhosis and episodes of recurrent acute cholangitis. Several endoscopic retrograde cholangiopancreatographies (ERCPs) with insertion of biliary plastic stents had been performed in another hospital.

Magnetic resonance cholangiography showed extrinsic compression of the main bile duct by a multicystic parasitic pseudotumor, associated with an intrahepatic necrotic parasitic cavity, in communication with dilated intrahepatic bile ducts, and containing gallstones (> Fig. 1).

Our management consisted of retrograde access of the major papilla, using an adult gastroscope, after going up the short afferent loop. The dilation of the main bile duct by the previous biliary stent procedures made it possible to perform cholangioscopy with the gastroscope. After crossing a relative extrinsic compression of the main bile duct, the endoscope accessed the necrotic cavity filled with biliary debris, into which multiple bile ducts flowed (> Fig. 2). Sludge and gallstones were removed with endoscopic baskets. A second cholangioscopy was then performed to complete the cleaning of the bile ducts with an exploration of each biliary branch with a balloon ( $\triangleright$ Fig. 3 ). At the end of this procedure, a biliary metal stent was positioned to treat the compression of the common bile duct ( $\triangleright$ Video 1 ).

Alveolar echinococcosis is a parasitic disease caused by Echinococcus multilocularis. The development of this parasitic infection causes the progressive appearance of intrahepatic pseudotumors. Radical surgery and liver transplantation are the only curative treatments. In $70 \%$ of cases, the treatment consists of a

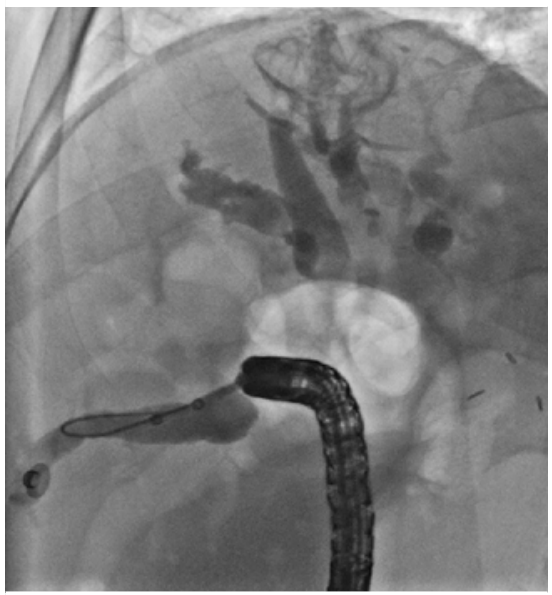

- Fig. 3 Radiographic image during cholangiography showing the exploration of a biliary branch with a balloon.
- Fig. 2 Views during cholangioscopy with the gastroscope showing: a compression of the main bile duct by the parasitic tumor; $\mathbf{b}$ the necrotic parasitic cavity and intrahepatic bile ducts with sludge and gallstones.

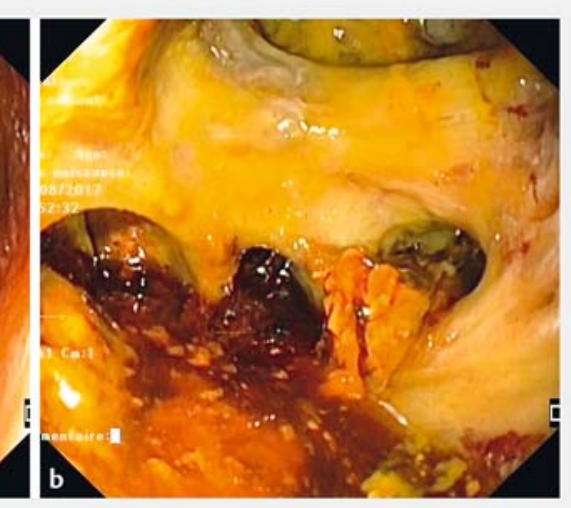




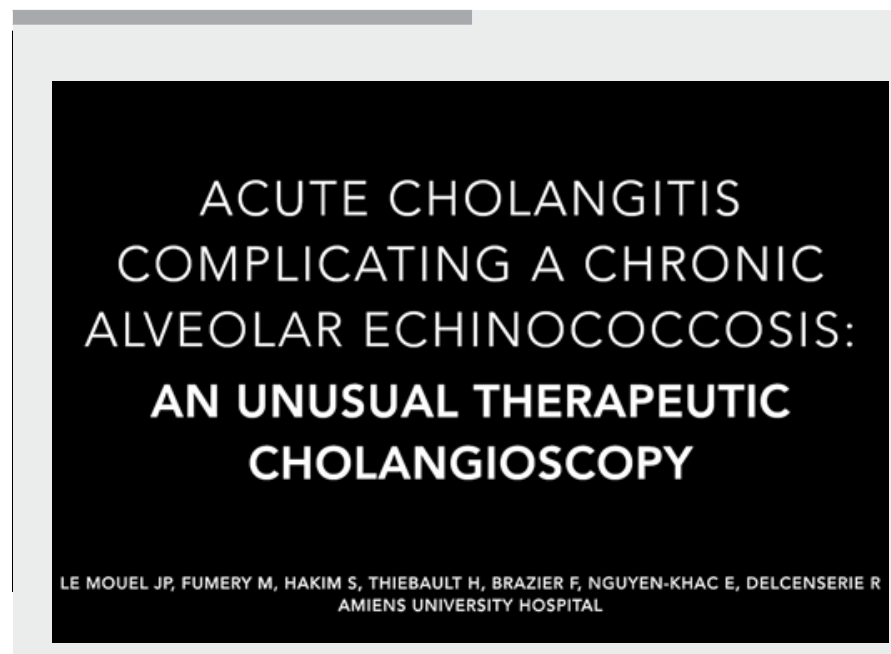

Video 1 Magnetic resonance cholangiography showing extrinsic compression of the main bile duct by a parasitic pseudotumor and an intrahepatic necrotic parasitic cavity. Cholangioscopy with a gastroscope allows removal of the gallstones and the sludge from the cavity, which is followed by exploration of the dilated bile ducts with a balloon.

combination of parasitostatic therapy and the punctual treatment of complications, such as biliary stenosis or intrahepatic gallstones. Current recommendations advise the use of endoscopic biliary drainage instead of surgery, even if iatrogenic cholangitis is more frequent with this (10\%). Placement of several plastic biliary stents optimizes drainage through the stenosis by decreasing stent occlusion [1].

Endoscopy_UCTN_Code_CCL_1AZ_2AN

Competing interests

\section{Reference}

[1] Ambregna S, Koch S, Sulz MC et al. A European survey of perendoscopic treatment of biliary complications in patients with alveolar echinococcosis. Expert Rev Anti Infect Ther 2017; 15: 79-88

Bibliography

DOI https://doi.org/10.1055/a-0624-1451

Published online: 12.6 .2018

Endoscopy 2018; 50: E214-E215

(c) Georg Thieme Verlag KG

Stuttgart · New York

ISSN 0013-726X

ENDOSCOPY E-VIDEOS

https:/|eref.thieme.de/e-videos

The authors

Jean-Phillip Le Mouel, Mathurin Fumery, Sami Hakim, Henri Thiebault, Franck Brazier, Eric Nguyen-Khac, Richard Delcenserie

Department of Hepato-Gastroenterology, Amiens University Hospital, Amiens, France

\section{Corresponding author}

Jean-Philippe Le Mouel, MD

Department of Hepato-Gastroenterology, Amiens University Hospital, Amiens, France jeanphilippe.lemouel@wanadoo.fr 